ALBERGARIA NETO, Jason; LOPES JÚNIOR, Newton de Araújo. O princípio constitucional da razoável duração do processo e a implementação do processo judicial eletrônico como forma de garantir celeridade aos litígios. Revista Eletrônica Direito e Política, Programa de Pós-Graduação Stricto Sensu em Ciência Jurídica da UNIVALI, Itajaí, v.16, n.1, 10 quadrimestre de 2021. Disponível em: www.univali.br/direitoepolitica - ISSN 1980-7791

\title{
O PRINCÍPIO CONSTITUCIONAL DA RAZOÁVEL DURAÇÃO DO PROCESSO E A IMPLEMENTAÇÃO DO PROCESSO JUDICIAL ELETRÔNICO COMO FORMA DE GARANTIR CELERIDADE AOS LITÍGIOS
}

\author{
THE CONSTITUTIONAL PRINCIPLE OF THE REASONABLE DURATION OF
} PROCEEDINGS AND THE IMPLEMENTATION OF THE ELECTRONIC JUDICIAL PROCESS AS A WAY OF ENSURING CELERITY TO DISPUTES

\author{
Jason Albergaria Neto ${ }^{1}$ \\ Newton de Araújo Lopes Júnior²
}

\section{RESUMO}

Objetivou-se com este trabalho tratar da informatização dos processos judiciais e da sua relação com a garantia constitucional da razoável duração do processo judicial. O problema da pesquisa cinge na implementação do processo eletrônico como forma de garantir a razoável duração do processo e suas consequências. O objetivo geral é demonstrar que simplesmente digitalizar e transferir os litígios judiciais para o meio eletrônico não é, necessariamente, capaz de garantir a razoável duração do processo. Em muitos casos, a falta de treinamento e de tecnologias para os membros da justiça podem acarretar maior morosidade do judiciário. Optou-se pela análise bibliográfica e jurisprudencial com suporte no método dedutivo. Como resultado observou-se que não basta transferir os autos físicos para o meio eletrônico. Restou comprovada a necessidade de investir em tecnologias e em treinamento da comunidade jurídica como um todo, para garantir ao jurisdicionado um resultado efetivo em tempo razoável.

PALAVRAS-CHAVE: Processo; Celeridade; Garantia constitucional; Informatização.

\footnotetext{
1 Doutor em Direito pela Universidade Federal de Minas Gerais - UFMG. Especialista em Direito Processual pela UFMG. Professor Titular de Processo Civil da Faculdade Milton Campos. Membro do Instituto de Direito Processual - IDpro. Membro da Comissão de Processo Civil da Ordem dos Advogados do Brasil - OAB/MG. Advogado e Procurador do Estado de Minas Gerais. Belo Horizonte, Minas Gerais, Brasil. E-mail: jasonalbergaria@gmail.com

2 Especialista em Direito Empresarial pela Pontifícia Universidade Católica de Minas Gerais PUC/MG. Mestrando em Direito nas Relações Econômicas e Sociais pela Faculdade Milton Campos. Advogado do escritório Advocacia Carlos Goulart. Belo Horizonte, Minas Gerais, Brasil. E-mail: newtonaljunior@yahoo.com.br
} 
ALBERGARIA NETO, Jason; LOPES JÚNIOR, Newton de Araújo. O princípio constitucional da razoável duração do processo e a implementação do processo judicial eletrônico como forma de garantir celeridade aos litígios. Revista Eletrônica Direito e Política, Programa de Pós-Graduação Stricto Sensu em Ciência Jurídica da UNIVALI, Itajaí, v.16, n.1, 10 quadrimestre de 2021. Disponível em: www.univali.br/direitoepolitica - ISSN 1980-7791

\section{ABSTRACT}

The objective of this work was to deal with the computerization of judicial proceedings and their relationship with the constitutional guarantee of the reasonable length of the proceedings. The research problem concerns the implementation of the electronic process as a way to guarantee the reasonable duration of the process and its consequences. The overall objective is to demonstrate that simply digitizing and transferring legal disputes to electronic media is not necessarily able to guarantee the reasonable duration of the process. In many cases, the lack of training and technologies for members of the justice system can lead to greater delays in the judiciary. We opted for bibliographic and jurisprudential analysis based on the deductive method. As a result, it was observed that it is not enough to transfer the physical records to the electronic medium. There remains a proven need to invest in technology and training for the legal community as a whole, in order to guarantee the jurisdiction an effective result within a reasonable time.

KEYWORDS: Process; Speed; Warranty; Constitutional; Computerization.

\section{INTRODUÇÃO}

Historicamente, a justiça brasileira sempre foi marcada por inúmeras reclamações em relação a real efetividade do poder judiciário nacional. Em virtude das diversas mudanças realizadas no processo judicial, tendo em vista sua crescente digitalização, tornou-se necessária a elaboração de novas legislações, criações de novos programas, investimentos em tecnologia, tempo de adaptação, dentre inúmeras mudanças para possibilitar que o processo eletrônico lograsse êxito, daí a crescente pressão para a unificação de programas em todos os âmbitos da justiça.

O assunto abordado no presente estudo, desperta curiosidade e interesse em virtude da necessidade de se respeitar diversos institutos jurídicos para implementação do processo judicial eletrônico, mas sempre visando dar maior celeridade aos processos judiciais.

No Brasil o processo eletrônico ainda está em fase de implementação, mas evidentemente por se tratar de inovação tecnológica em área sabidamente 
ALBERGARIA NETO, Jason; LOPES JÚNIOR, Newton de Araújo. O princípio constitucional da razoável duração do processo e a implementação do processo judicial eletrônico como forma de garantir celeridade aos litígios. Revista Eletrônica Direito e Política, Programa de Pós-Graduação Stricto Sensu em Ciência Jurídica da UNIVALI, Itajaí, v.16, n.1, 10 quadrimestre de 2021. Disponível em: www.univali.br/direitoepolitica - ISSN 1980-7791

conservadora, vêm sendo duramente criticado, basta ver as inúmeras plataformas existentes dentro dos tribunais.

Ao longo deste artigo, buscou-se destacar o surgimento do processo eletrônico, a importância da garantia razoável duração do processo, os problemas gerados pelo congestionamento de processos no sistema judicial pátrio e pôr fim a importância da implementação do processo eletrônico desde que acompanhado de inúmeras outras práticas, tais como: investimentos em tecnologia, investimentos em pessoal treinado e implementação de forma gradativa.

O problema da pesquisa na expectativa criada pela implementação do processo eletrônico como única forma de garantir a razoável duração do processo judicial e suas consequências.

Diante de tal cenário, o trabalho faz um levantamento sobre alguns dos problemas existentes e consequentemente cita dados do Conselho Nacional de Justiça que demonstram que a situação da justiça brasileira é gravíssima, aduz ainda que não basta a digitalização de processos para solucionar todos os problemas relacionados a efetividade de justiça, sugere que haja um esforço coletivo de todos os operadores do direitos com o intuito de reduzir o acervo processual.

Conjeturando sobre a antinomia entre a inovação tecnológica e a práxis, resta a dúvida: qual seria o ponto de equilíbrio para garantir a razoável duração do processo e ao mesmo tempo informatizar todos os processos judiciais? Como alcançar a total digitalização dos autos processuais, mas sempre possibilitando a interação das partes e participação?

Partindo desse tema-problema (contradições existentes entre a implementação do processo eletrônico e a expectativa criada em acelerar todos os processos judiciais), o trabalho apresenta a hipótese que aborda sobre a implementação de tecnologias no judiciário para tentar-se atingir um processo mais célere, mas que possibilite as partes e membros do judiciário facilidades e simplificação de procedimentos. 
ALBERGARIA NETO, Jason; LOPES JÚNIOR, Newton de Araújo. O princípio constitucional da razoável duração do processo e a implementação do processo judicial eletrônico como forma de garantir celeridade aos litígios. Revista Eletrônica Direito e Política, Programa de Pós-Graduação Stricto Sensu em Ciência Jurídica da UNIVALI, Itajaí, v.16, n.1, 10 quadrimestre de 2021. Disponível em: www.univali.br/direitoepolitica - ISSN 1980-7791

O artigo tem como objetivo geral demonstrar que não necessariamente a digitalização e transferência dos litígios judiciais pura e simplesmente para o meio eletrônico, são capazes de garantir a razoável duração do processo. Em muitos casos a falta de treinamento e tecnologias para os membros da justiça podem acarretar maior morosidade do judiciário.

Os objetivos específicos do trabalho visam: apontar as situações criadas pela informatização dos processos judiciais no que tange a celeridade do processo, analisar a implementação do processo eletrônico em outros países, além disso demonstrar que a tecnologia será importante ferramenta para padronizar o tramite de processos e facilitar a atuação de magistrados, servidores, advogados, estagiários, mas que não basta digitalizar os processos para solucionar todas as questões.

Metodologicamente, priorizou-se pela pesquisa hipotético-dedutivo do problema fático-jurídico, embasado de métodos jurídico-dogmáticos além da análise doutrinária.

O artigo adota como marco teórico basilar o axioma de Alexandre Atheniense e sua reflexão sobre as práticas processuais por meio eletrônico no sistema judicial brasileiro, seu aprimoramento, seus fundamentos e sistematização.

Por fim é debatido ainda a implementação de diferentes plataformas do sistema eletrônico, como por exemplo no Egrégio Tribunal de Justiça de Minas Gerais para confirmar a hipótese apresentada e comprovar que o processo judicial eletrônico é importante ferramenta para garantir a razoável duração do processo além de ser protagonista no cenário nacional ao atuar como principal mecanismo para diminuir o tempo dos processos judiciais, entretanto fica o alerta que são necessárias inúmeras outras medidas de forma simultânea para redução do acervo de processos judiciais no ordenamento pátrio. 
ALBERGARIA NETO, Jason; LOPES JÚNIOR, Newton de Araújo. O princípio constitucional da razoável duração do processo e a implementação do processo judicial eletrônico como forma de garantir celeridade aos litígios. Revista Eletrônica Direito e Política, Programa de Pós-Graduação Stricto Sensu em Ciência Jurídica da UNIVALI, Itajaí, v.16, n.1, 10 quadrimestre de 2021. Disponível em: www.univali.br/direitoepolitica - ISSN 1980-7791

\section{A RAZOÁVEL DURAÇÃo do PROCESSO COMO GARANTIA CONSTITUCIONAL}

Desde a aprovação pela Assembleia Nacional Constituinte da sétima Constituição Federal do Brasil em 1988, inúmeras alterações e emendas foram realizadas, dentre elas várias que mudanças que modificaram o funcionamento do sistema judiciário pátrio.

Dentre elas, importante destacar a Emenda Constitucional no 45/2004 que assegurou como garantia constitucional a razoável duração do processo e os meios que garantam a celeridade de sua tramitação, especificamente no art. 50, LXXVIII:

Art. 50. LXXVIII a todos, no âmbito judicial e administrativo, são assegurados a razoável duração do processo e os meios que garantam a celeridade de sua tramitação. (Incluído pela Emenda Constitucional no 45, de 2004) ${ }^{3}$

Qual seria a importância de um processo célere e qual sua conexão com a constituição? Trata-se de questão intrínseca aos direitos dos cidadãos, afinal o jurisdicionado ao pedir ajuda ao judiciário sinaliza toda sua dependência estatal para garantir direitos que de certa forma foram privados, sejam eles: direitos de posse, direitos difusos, direitos da vida civil dente os inúmeros ramos do direito.

Um processo judicial justo e célere é imperioso para que uma sociedade logre êxito como nação desenvolvida e de primeiro mundo, o estado detém o poder jurisdicional que decorre de sua soberania, exatamente para resguardar direitos, editar leis e ministrar a justiça, os cidadãos recorrem a justiça porque dependem dela para atingir determinado fim.

3 BRASIL. Constituição (1988). Emenda constitucional no 45, de 30 de dezembro de 2004. Disponível em: <http://www.planalto.gov.br/ccivil_03/constituicao/emendas/emc/emc45.htm>. Acesso em: 27 jan. 2020. 
ALBERGARIA NETO, Jason; LOPES JÚNIOR, Newton de Araújo. O princípio constitucional da razoável duração do processo e a implementação do processo judicial eletrônico como forma de garantir celeridade aos litígios. Revista Eletrônica Direito e Política, Programa de Pós-Graduação Stricto Sensu em Ciência Jurídica da UNIVALI, Itajaí, v.16, n.1, 10 quadrimestre de 2021. Disponível em: www.univali.br/direitoepolitica - ISSN 1980-7791

A razoável duração do processo está diretamente ligada a ideia de justiça, afinal uma justiça lenta e morosa nada mais é que injustiça institucionalizada. Rui Barbosa, ao abordar a ideia de justiça atrasada, nos fez a reflexão em Oração aos Moços:

\begin{abstract}
Destarte se incrementa e desmanda ele em proporções incalculáveis, chegando as causas a contar a idade por lustros, ou décadas, em vez de anos.

Mas justiça atrasada não é justiça, senão injustiça qualificada e manifesta. Porque a dilação ilegal nas mãos do julgador contraria o direito escrito das partes, e, assim, as lesa no patrimônio, honra e liberdade. Os juízes tardinheiros são culpados, que a lassidão comum vai tolerando. Mas sua culpa tresdobra com a terrível agravante de que o lesado não tem meio de reagir contra o delinquente poderoso, em cujas mãos jaz a sorte do litígio pendente... ${ }^{4}$
\end{abstract}

A necessidade de garantir um resultado prático é salientada pelos mais notórios processualistas brasileiros, na linha do tempo e do espaço, daí a inclusão da razoável duração do processo no rol dos princípios constitucionais.

Nas palavras de Humberto Theodoro Júnior "não é suficiente ao ideal de justiça garantir a solução judicial para todos os conflitos; o que é imprescindível é que essa solução seja efetivamente justa, isto é, apta, útil e eficaz."5

Imperiosa a necessidade de possibilitar que os cidadãos que demandam a ajuda da justiça alcancem um resultado prático e realmente efetivo no que tange a proteção de seus direitos, seja a proteção de pessoas, bens dentre outros.

O poder judiciário nada mais é que a ferramenta para resguardar direitos, garantir obrigações, impor que os membros da sociedade cumpram com seus deveres legais e quando necessária seja capaz de dar sanções a tempo e a modo eficientes, a ideia de justiça morosa impacta diretamente na tutela de direitos.

\footnotetext{
4 BARBOSA, Rui. Oração aos moços. Edição popular anotada por Adriano da Gama Kury. 5 ed. Rio de Janeiro: 1997, p. 40.

5 THEODORO JÚNIOR, Humberto. Curso de Direito Processual Civil. 36 ed. v. II. Rio de Janeiro: Forense, 2004, p. 350.
} 
ALBERGARIA NETO, Jason; LOPES JÚNIOR, Newton de Araújo. O princípio constitucional da razoável duração do processo e a implementação do processo judicial eletrônico como forma de garantir celeridade aos litígios. Revista Eletrônica Direito e Política, Programa de Pós-Graduação Stricto Sensu em Ciência Jurídica da UNIVALI, Itajaí, v.16, n.1, 10 quadrimestre de 2021. Disponível em: www.univali.br/direitoepolitica - ISSN 1980-7791

Nesse diapasão aponta José Rogério Cruz e Tucci:

Relegando a um plano secundário as construções de cunho teórico, que tanta relevância ostentaram até há bem pouco tempo, os processualistas passaram a preocupar-se com um valor fundamental, ínsito à tutela dos direitos, qual seja, a imprescindibilidade da efetividade do processo, enquanto instrumento de realização da justiça.

Como adverte, a propósito, Barbosa Moreira, 'toma-se consciência cada vez mais clara da função instrumental do processo e da necessidade de fazê-lo desempenhar de maneira efetiva o papel que lhe toca.

É, pois, preciso oferecer ao processo mecanismos que permitam o cumprimento de toda a sua missão institucional, evitando-se que seja considerado 'fonte perene de decepções' ${ }^{6}$

$\mathrm{Na}$ sociedade contemporânea é cada vez mais forte a corrente doutrinária e jurisprudencial que defende a tese que o processo civil e suas normas devem ser regidos e guiados pelas garantias/direitos fundamentais constitucionais, bem como obedecer a forma normativa da Magna Carta.

A informatização de processos vem sendo implementada como a solução de inúmeros problemas da justiça, tratada como a ferramenta que irá diminuir os milhares de estoques processuais existentes e reduzirá drasticamente o tempo de tramitação dos feitos no ordenamento jurídico brasileiro.

Atualmente, existe uma forte corrente no processo civil especialmente que trata sobre a denominada constitucionalização do processo civil, ou seja, busca harmonizar princípios constitucionais como o da razoável duração do processo e o processo.

Diante de tal situação um fenômeno denominado neoconstitucionalismo ganhou força entre os operadores do direito, fenômeno esse que nada mais é que garantir a Constituição Federal um protagonismo que a coloque no centro de todos os ramos do Direito e no processo civil não é diferente.

Esclarece sobre esse fenômeno Pedro Lenza:

${ }^{6}$ TUCCI, José Rogério Cruz e. Tempo e processo. São Paulo: Revista dos Tribunais, 1997, p. 63. 
ALBERGARIA NETO, Jason; LOPES JÚNIOR, Newton de Araújo. O princípio constitucional da razoável duração do processo e a implementação do processo judicial eletrônico como forma de garantir celeridade aos litígios. Revista Eletrônica Direito e Política, Programa de Pós-Graduação Stricto Sensu em Ciência Jurídica da UNIVALI, Itajaí, v.16, n.1, 10 quadrimestre de 2021. Disponível em: www.univali.br/direitoepolitica - ISSN 1980-7791

Não mais apenas atrelar o constitucionalismo à ideia de limitação do poder político, mas, acima de tudo buscar a eficácia da constituição, deixando o texto de ter um caráter meramente retórico e passando a ser mais efetivo, especialmente diante da experiência de concretização dos direitos fundamentais. ${ }^{7}$

O que se percebe é uma crescente preocupação em garantir que os direitos fundamentais sejam respeitados, mas não só isso, visa-se com essas alterações a preservação de direitos fundamentais, inclusive no âmbito do processo civil e o processo eletrônico vem como uma das ferramentas que promete garantir eficácia e celeridade aos processos.

Nesse mesmo sentido a ideia central de que o processo civil deve ser o meio para atingir o fim, que é a efetividade do poder judiciário, daí a importância do poder judiciário quando provocado dar a devida resposta com efetividade como se infere em Humberto Theodoro Júnior:

A fonte imediata do processo civil não é mais apenas o Código, é, antes de tudo, a própria Constituição, em que sem acham enunciados, como direitos fundamentais, os princípios sobre os quais se ergue o processo de atuação da jurisdição civil. Da constituição emergem os requisitos do processo justo, o qual supera, em profundidade, o feitio preponderante procedimental da antiga visão do devido processo legal. Deixa esse moderno processo tipificado pelo novo constitucionalismo, construído pelo Estado Democrático de Direito, de ser tratado como simples instrumento técnico de aplicação da lei para tornar-se um sistema constitucional de tutela de direito, sempre que lesados ou ameaçados. $^{8}$

No mesmo sentido, Luiz Rodrigues Wambier em conjunto com Teresa Arruda Alvim Wambier - relatora do projeto do NCPC - aduz sobre a Lei 13.105/2015 e destaca a expressa inserção de princípios constitucionais no processo civil:

Modificações foram feitas no projeto original, para alterar rumos ou para dar respostas ao embate democrático que enfim, permitiu sua aprovação. Essas diretrizes estão elencadas na Exposição de

7 LENZA, Pedro. Direito Constitucional esquematizado. 16a ed. São Paulo: Saraiva, 2012, p. 62.

8 THEODORO JÚNIOR, Humberto. Curso de Direito Processual Civil - Teoria Geral do Direito Processual Civil, processo de conhecimento e procedimento comum. v. I. 56 ed. Rio de Janeiro: Forense, 2015, p. 69. 
ALBERGARIA NETO, Jason; LOPES JÚNIOR, Newton de Araújo. O princípio constitucional da razoável duração do processo e a implementação do processo judicial eletrônico como forma de garantir celeridade aos litígios. Revista Eletrônica Direito e Política, Programa de Pós-Graduação Stricto Sensu em Ciência Jurídica da UNIVALI, Itajaí, v.16, n.1, 10 quadrimestre de 2021. Disponível em: www.univali.br/direitoepolitica - ISSN 1980-7791

Motivos: 1) estabelecer expressa implicitamente verdadeira sintonia fina com a Constituição Federal. ${ }^{9}$

Dessa forma, verifica-se que o processo eletrônico tem sido tratado como a "menina dos olhos" dos tribunais de justiça e do Conselho Nacional de Justiça, mas a grande questão é se essa grande expectativa na informatização da justiça não é exagerada, afinal, não basta digitalizar processos, é necessário um conjunto de providências que devem ser executadas em harmonia para que se atinja um processo cada vez mais eficaz e justo.

\section{OS PRIMEIROS PASSOS DO PROCESSO ELETRÔNICO NO BRASIL}

A utilização de mecanismos digitais para a tramitação de processos judiciais no Brasil não foi uma novidade instaurada pela Lei 11.419/2006, desde meados da década de 90 já havia essa previsão legal, como por exemplo na Lei do Inquilinato em seu artigo 58 que permitiu o uso de tecnologias para transmissão de citações, intimações, notificações das partes.

Entretanto para muitos doutrinadores a pedra fundamental do processo eletrônico pátrio, foi a promulgação da Lei 9.800/99 que possibilitou que às partes utilizassem de sistema de transmissão de dados e imagens tipo fac-símile para a realização de atos processuais antes deveria ser realizado por petição escrita.

A ressalva existente era no sentido de obrigar a parte que fizesse uso de tal tecnologia de se responsabilizar pela qualidade e fidelidade do material transmitido, inclusive pela sua entrega, mesmo assim tratava-se de importante inovação processual.

Diante dessa possibilidade os Juizados Especiais Federais (Lei 10.259/2001) começaram a utilizar essa tecnologia para resolução dos litígios.

\footnotetext{
9 WAMBIER, Luiz Rodrigues; WAMBIER, Teresa Arruda Alvim (Coord.). Temas essenciais do novo CPC: análise das principais alterações do sistema processual civil brasileiro. São Paulo: Editora Revista dos Tribunais, 2016, pp. 41-42.
} 
ALBERGARIA NETO, Jason; LOPES JÚNIOR, Newton de Araújo. O princípio constitucional da razoável duração do processo e a implementação do processo judicial eletrônico como forma de garantir celeridade aos litígios. Revista Eletrônica Direito e Política, Programa de Pós-Graduação Stricto Sensu em Ciência Jurídica da UNIVALI, Itajaí, v.16, n.1, 10 quadrimestre de 2021. Disponível em: www.univali.br/direitoepolitica - ISSN 1980-7791

Em virtude dos autos serem integralmente digitais demandaria que as partes fossem responsabilizadas pelos atos processuais, juntadas, assinaturas, inserção e sua respectiva autenticidade.

Após o envio de um ofício da Associação dos Juízes Federais do Brasil (AJUFE) que deu origem ao projeto de Lei no 5.828 que buscava informatizar a justiça e regulamentar a utilização de novas tecnologias no âmbito judiciário.

Tal projeto sofreu inúmeros reparos tendo como base a experiência realizada nos Juizados Especiais, fato que eclodiu na nova Lei sobre a informatização do processo judicial.

Com vistas a transformar o processo civil e a prestação jurisdicional mais célere, objetivando garantir mais rapidez nas decisões aos jurisdicionados, foi aprovada a Lei de no 11.419/2006 que dispôs sobre a informatização do processo judicial; alterou o Código de Processo Civil vigente à época e permitiu outras providências.

Uma das grandes inovações da referida lei foi o artigo $8^{\circ}$ que disciplinou sobre a possibilidade de que os órgãos do poder judiciário pudessem desenvolver sistemas eletrônicos de processamento de ações judiciais por intermédio da rede mundial de computadores:

Art. $8^{\circ}$ Os órgãos do Poder Judiciário poderão desenvolver sistemas eletrônicos de processamento de ações judiciais por meio de autos total ou parcialmente digitais, utilizando, preferencialmente, a rede mundial de computadores e acesso por meio de redes internas e externas.

Parágrafo único. Todos os atos processuais do processo eletrônico serão assinados eletronicamente na forma estabelecida nesta Lei. ${ }^{10}$

10 BRASIL. Lei no $\mathbf{1 1 . 4 1 9}$, de 19 de dezembro de 2006. Disponível em: <http://www.planalto.gov.br/ccivil_03/_ato2004-2006/2006/lei/l11419.htm>. Acesso em: 27 jan. 2020. 
ALBERGARIA NETO, Jason; LOPES JÚNIOR, Newton de Araújo. O princípio constitucional da razoável duração do processo e a implementação do processo judicial eletrônico como forma de garantir celeridade aos litígios. Revista Eletrônica Direito e Política, Programa de Pós-Graduação Stricto Sensu em Ciência Jurídica da UNIVALI, Itajaí, v.16, n.1, 10 quadrimestre de 2021. Disponível em: www.univali.br/direitoepolitica - ISSN 1980-7791

Desde os primórdios da informatização dos processos judiciais e implementação dos sistemas eletrônicos no ordenamento jurídico brasileiro se faz a ressalva dos problemas existentes entre as diferentes plataformas utilizadas pelos Tribunais espalhados pelo Brasil, independente das características de cada região o risco seria tornar o processo civil e por conseguinte o processo eletrônico regional.

Nas palavras de José Carlos de Araújo Almeida Filho:

Um alerta importante: como vivemos em um país de dimensões continentais, a sistemática do processo eletrônico deverá obedecer a cada região, sob pena de termos graves problemas de aplicação. Contudo, não podemos admitir regulamentações sobre toda uma sistemática processual, porque estaríamos retroagindo aos Códigos de Processo estaduais, o que proporcionará um grande atraso em todos os sistemas. ${ }^{11}$

A importância do processo eletrônico como mecanismos eficaz para garantir a razoável duração do processo é evidente, afinal desde que a informatização da justiça seja implementada de forma ordenada e correta, certamente a a informática terá papel de protagonismo na tentativa de acelerar o tramite dos litígios.

É questão sabida por todos, até por aqueles que não laboram no ramo do direito que a justiça pátria sofre em demasia com o excesso de burocracia, excesso de procedimentos, existe um evidente problema a ser sanado, e sim, o processo eletrônico pode desencadear uma mudança histórica no processo judicial brasileiro.

Nesse diapasão José Carlos de Araújo Almeida Filho comenta que:

Assim como ocorre na arbitragem e guardadas as devidas proporções porque o processo eletrônico não é meio alternativo de solução de conflitos, o processo eletrônico pode ser muito bem utilizado por aqueles que têm acesso aos meios da Informática.

11 ALMEIDA FILHO, José Carlos de Araújo. Processo eletrônico e teoria geral do processo eletrônico: a informatização judicial no Brasil. 1a ed. Rio Janeiro: Forense, 2007, p. 355. 
ALBERGARIA NETO, Jason; LOPES JÚNIOR, Newton de Araújo. O princípio constitucional da razoável duração do processo e a implementação do processo judicial eletrônico como forma de garantir celeridade aos litígios. Revista Eletrônica Direito e Política, Programa de Pós-Graduação Stricto Sensu em Ciência Jurídica da UNIVALI, Itajaí, v.16, n.1, 10 quadrimestre de 2021. Disponível em: www.univali.br/direitoepolitica - ISSN 1980-7791

Como forma de desafogar o Judiciário e até mesmo eliminar os entreves burocráticos havidos nos cartórios, a população mais carente teria maior acessibilidade a todos os meios para concretização de seus direitos. Um procedimento eletrônico é rápido e eficaz e as experiências vivenciadas no Brasil demonstraram serem possível a inserção desta forma ao processo. ${ }^{12}$

Ora como se vê o processo judicial eletrônico e suas legislações surgiram com a promessa de acelerar procedimentos, diminuir etapas processuais e até possibilitar que o jurisdicionado menos favorecido tenha uma solução mais rápida para seus problemas.

Ocorre que, existem inúmeras situações durante o trâmite processual que podem e devem ser aceleradas pelo processo eletrônico, o estado é o titular da jurisdição e pode disciplinar sobre essas questões, como por exemplo despachos simples de vista sucessiva as partes, afinal ambas as partes conseguem acessar aos autos simultaneamente.

O magistrado é capaz de dirimir determinadas questões sem a obrigação legal de necessariamente esperar a manifestação das partes em meio físico, como por exemplo em situações que a legislação anterior permite a decisão ex ofício.

Os princípios e garantias constitucionais não só podem como devem ser harmônicos entre si, sem que nenhum deles se sobreponha ao outro, mas resta evidente que o sistema judicial pátrio necessita de maior eficácia e celeridade.

A razoável duração do processo e a solução integral do litígio, são garantias que com a promulgação do novo Código de Processo Civil constam taxativamente na lei, especificamente no artigo $4^{\circ}$ da Lei $13.105 / 2015$ "Art. $4^{\circ}$ As partes têm o

12 ALMEIDA FILHO, José Carlos de Araújo. Processo eletrônico e teoria geral do processo eletrônico: a informatização judicial no Brasil. p. 25. 
ALBERGARIA NETO, Jason; LOPES JÚNIOR, Newton de Araújo. O princípio constitucional da razoável duração do processo e a implementação do processo judicial eletrônico como forma de garantir celeridade aos litígios. Revista Eletrônica Direito e Política, Programa de Pós-Graduação Stricto Sensu em Ciência Jurídica da UNIVALI, Itajaí, v.16, n.1, 10 quadrimestre de 2021. Disponível em: www.univali.br/direitoepolitica - ISSN 1980-7791

direito de obter em prazo razoável a solução integral do mérito, incluída a atividade satisfativa"13 (grifos nossos).

O artigo supracitado inclusive disciplina que não basta a solução de mérito no processo de conhecimento, mas também é essencial que a atividade satisfativa seja cumprida, ou seja, tenta evitar que ocorra o tão conhecido "ganhou, mas não levou" que infelizmente é recorrente no ordenamento jurídico brasileiro.

Sobre a importância da real celeridade da justiça assim preceitua Elpídio Donizetti:

Apesar de a EC no 45/2004 ter trazido diversos mecanismos visando à celeridade na prestação jurisdicional, como por exemplo, as súmulas vinculantes, a vedação de férias coletivos nos juízos e tribunais de segundo grau, a distribuição imediata de processos em todos os graus de jurisdição e necessidade de demonstração de repercussão geral nas questões levadas ao Supremo Tribunal Federal, ainda há muito que ser feito pelos três Poderes para que a Justiça seja efetivamente célere. ${ }^{14}$

O surgimento do processo eletrônico no Brasil vem para mudar a ideia do processo, mas pelo que se vê demanda maiores estudos, maiores investimentos e principalmente maior foco no capital humano que irá lidar com as novas tecnologias, afinal, não basta existir um computador de última geração e um software extremamente moderno - o que também não é o caso diga-se de passagem - é fundamental especializar o capital humano, treinar os servidores, advogados, dentre outros profissionais.

O Brasil pode e deve continuar avançando no quesito de informatização do processo eletrônico, mas como em muitos outros casos o início tardio das implementações demanda tempo, esforço e principalmente investimento, a grande preocupação desde o seu surgimento está diretamente ligada aos

13 BRASIL. Lei 13.105, de 16 de março de 2015. Código de Processo Civil de 2015. Disponível em: <http://www.planalto.gov.br/ccivil_03/_Ato2015-2018/2015/Lei/L13105.htm>. Acesso em 08 de junho de 2019.

${ }^{14}$ DONIZETTI, Elpídio. Curso de direito processual civil. 19 a ed. São Paulo: Atlas, 2016, p. 40. 
ALBERGARIA NETO, Jason; LOPES JÚNIOR, Newton de Araújo. O princípio constitucional da razoável duração do processo e a implementação do processo judicial eletrônico como forma de garantir celeridade aos litígios. Revista Eletrônica Direito e Política, Programa de Pós-Graduação Stricto Sensu em Ciência Jurídica da UNIVALI, Itajaí, v.16, n.1, 10 quadrimestre de 2021. Disponível em: www.univali.br/direitoepolitica - ISSN 1980-7791

problemas enfrentados pelo poder público e a expectativa criada com a digitalização de processos em larga escala.

\section{O SURGIMENTO DO PROCESSO ELETRÔNICO EM OUTROS PAÍSES}

Apesar do processo eletrônico brasileiro ser relativamente novo em relação a outros países em que a informatização do processo judicial começou no final do século passado, imperioso destacar que em quase todos os países o processo eletrônico vem sofrendo constantes e importantes mudanças em seu funcionamento.

Em Portugal por exemplo que foi um dos pioneiros na prática processual por meio eletrônico no final do século passado já se permitia a prática de diversos atos por e-mail como por plataformas online, o grande avanço no processo eletrônico português se deu no que tange a assinatura com certificação digital.

Em Portugal a Ordem dos Advogados Portuguesa na época contratou em 1999 uma empresa denominada MultCert para operacionalizar a emissão de certificados que seriam utilizados mais tarde para envio e processamento de dados no processo eletrônico, como se vê na obra de Alexandre Atheniense:

A ordem dos advogados (de Portugal) contratou a empresa MultCert, que até a presente data emite os certificados dos advogados portugueses, que tem um grau 3, sendo portanto, qualificados com grau de segurança maior do que a própria lei portuguesa impunha $[\ldots]$

Assim, Portugal foi um dos primeiros países a se adequar a essas disposições no tocante à implementação do processo eletrônico, sobretudo na produção de atos processuais por esse meio, mediante a assinatura eletrônica com a utilização de um certificado avançado. ${ }^{15}$

15 ATHENIENSE, Alexandre. Comentários à Lei 11.419/06 e as práticas processuais por meio eletrônico nos Tribunais brasileiros. Curitiba: Juruá Editora, 2010, p. 69. 
ALBERGARIA NETO, Jason; LOPES JÚNIOR, Newton de Araújo. O princípio constitucional da razoável duração do processo e a implementação do processo judicial eletrônico como forma de garantir celeridade aos litígios. Revista Eletrônica Direito e Política, Programa de Pós-Graduação Stricto Sensu em Ciência Jurídica da UNIVALI, Itajaí, v.16, n.1, 10 quadrimestre de 2021. Disponível em: www.univali.br/direitoepolitica - ISSN 1980-7791

Depois de inúmeras inovações e tentativas, a Justiça portuguesa implementou o sistema Citius que do latim quer dizer célere, trata-se do sistema utilizado para informatizar todo o processo português.

Como se vê no sumário da Portaria de 280/2013 assinada pela Ministra da Justiça Paula Maria von Hafe Teixeira da Cruz em que menciona a importância do processo eletrônico e a adoção do sistema Citius para resolução de litígios.

É o caso da tramitação eletrônica de processos, até aqui regulamentada pela Portaria n. ${ }^{\circ} 114 / 2008$, de 6 de fevereiro.

As alterações ora introduzidas a esse regime não são muito significativas, até porque a utilização de sistemas informáticos para a tramitação eletrônica de processos tem-se revelado, em Portugal, uma experiência bem-sucedida, com larga aceitação entre os profissionais forenses que diariamente utilizam o sistema informático de suporte à atividade dos tribunais. ${ }^{16}$

Resta evidente que no processo civil moderno a informática é protagonista em quase todos os países desenvolvidos. Na Espanha por exemplo, a iniciativa para acelerar e facilitar a vida dos advogados teve início com a Advocacia Institucional que é uma espécie de Ordem dos Advogados Espanhola.

A ideia inicial era permitir que os advogados pudessem poupar tempo e otimizar as tarefas diárias dos advogados, surgiram então duas plataformas, a ACAAutoridad de Certificación de la Abogacía e a REd Abogacía.

$\mathrm{Na}$ Espanha até hoje se utiliza a Red Abogacia para realizar inúmeros procedimentos relacionados a administração pública, como por exemplo, possibilitar a entrada do advogado em prisões, remessa de documentos etc.

Existem ainda inúmeras outras plataformas digitais espanholas, tais como a SIGA - Sistema Integrado de Gestão da Advocacia, além de um dos mais importantes denominado LexNet, utilizado para assinatura eletrônica,

16 PORTUGAL. Procuradoria Geral Distrital de Lisboa. Portaria 280, de 26 de agosto de 2013. Regula vários aspectos da tramitação eletrônica dos processos judiciais. Disponível em: <http://www.pgdlisboa.pt/leis/lei_mostra_articulado.php?nid=1967\&tabela=leis\&so_miolo=>. Acesso em: 26 jun. 2019. 
ALBERGARIA NETO, Jason; LOPES JÚNIOR, Newton de Araújo. O princípio constitucional da razoável duração do processo e a implementação do processo judicial eletrônico como forma de garantir celeridade aos litígios. Revista Eletrônica Direito e Política, Programa de Pós-Graduação Stricto Sensu em Ciência Jurídica da UNIVALI, Itajaí, v.16, n.1, 10 quadrimestre de 2021. Disponível em: www.univali.br/direitoepolitica - ISSN 1980-7791

recebimento de intimações, pode-se inclusive distribuir processos pelo sistema de forma rápida e segura.

O Ministério da Justiça Espanhol inclusive tem dado muita atenção ao desenvolvimento de sistemas que possam facilitar a operação e reduzir o tempo dos processos na justiça espanhola.

Já no Estados Unidos da América o processo eletrônico começou de forma diferente, foi criado um sistema em âmbito federal o denominado CM/ECF que permitia o controle de processos das cortes americanas e que era composto por um sistema denominado Pacer.

Entretanto em virtude de a legislação americana permitir a regulamentação por cada ente estadual, a implementação do processo eletrônico se deu de forma diferente nos estados, pode-se citar alguns dos estados pioneiros em relação a digitalização do processo eletrônico, tais como: Alabama, Arizona, Califórnia, Colorado, Delaware, Nova Iorque, Ohio, Texas.

O uso de fac-símile também foi utilizado nos EUA para envio de documentos por meios eletrônicos, ou seja, o que se vê são ferramentas diferentes, programas com versões distintas, mas que possuem intuito semelhante, qual seja, desburocratizar os processos e evidentemente garantir maior celeridade a justiça.

Trata-se de desafio presente em todo o mundo, atingir um processo justo, mas em tempo razoável, possibilitando que as partes consigam tutelar seus direitos em período hábil, afinal a ideia de justiça independente do país está diretamente ligada a efetividade do sistema. 
ALBERGARIA NETO, Jason; LOPES JÚNIOR, Newton de Araújo. O princípio constitucional da razoável duração do processo e a implementação do processo judicial eletrônico como forma de garantir celeridade aos litígios. Revista Eletrônica Direito e Política, Programa de Pós-Graduação Stricto Sensu em Ciência Jurídica da UNIVALI, Itajaí, v.16, n.1, 10 quadrimestre de 2021. Disponível em: www.univali.br/direitoepolitica - ISSN 1980-7791

\section{A IMPORTÂNCIA DO PROCESSO ELETRÔNICO PARA DIMINUIR A TAXA DE CONGESTIONAMENTO DA JUSTIÇA BRASILEIRA}

Atualmente resta evidente que o judiciário brasileiro está congestionado, são milhares de processos de todos os tipos, classes, matérias, partes aguardando uma solução.

De acordo com o relatório da justiça em números elaborado pelo Conselho Nacional de Justiça em 2018, tendo como ano-base 2017, o poder judiciário finalizou o ano de 2017 com 80,1 milhões de processos em tramitação, além disso, analisando a série histórica no período de 2009-2017 o acumulado no período é de $31,9 \%$ de processos, ou seja, um acréscimo de 19,4 milhões de processos.

Verificando os dados por segmento de justiça, a Justiça Estadual é o grande gargalo dos processos pendentes, atingindo $79,3 \%$ dos autos pendentes de julgamento.

No ritmo atual das demandas restou comprovado que mesmo que não houvesse novas demandas e a produtividade dos servidores do judiciário continuasse no ritmo atual, somente após 31 meses o estoque de processos seria zerado, o número é alarmante.

Daí a importância de se inserir o processo eletrônico como forma de diminuir esses alarmantes números, a informatização dos tribunais pode e deve ser o grande protagonista para resolução desse grave problema.

Entre os operadores do direito, doutrinadores, servidores, juízes é unânime que alcançar a tutela satisfativa, é um dos grandes problemas do ordenamento pátrio, as execuções independentes se fiscais, penais, cíveis ou de títulos extrajudiciais em muitos dos casos não atingem seu fim.

São as execuções que correspondem a $53 \%$ dos processos pendentes no país, são várias as situações que a obrigatoriedade da oitiva das partes pode 
ALBERGARIA NETO, Jason; LOPES JÚNIOR, Newton de Araújo. O princípio constitucional da razoável duração do processo e a implementação do processo judicial eletrônico como forma de garantir celeridade aos litígios. Revista Eletrônica Direito e Política, Programa de Pós-Graduação Stricto Sensu em Ciência Jurídica da UNIVALI, Itajaí, v.16, n.1, 10 quadrimestre de 2021. Disponível em: www.univali.br/direitoepolitica - ISSN 1980-7791

prejudicar o resultado útil do processo, basta ver que dos $53 \%$ dos processos pendentes $74 \%$ delas são execuções fiscais que sabidamente em muitas situações são extintas de ofício.

São milhares de processos que podem ter o devido andamento por meio eletrônico, o grande problema está na falta de treinamento dos servidores, falta de equipamentos e ainda o grande estoque de processos físicos existentes, principalmente porque em muitos casos, as citações e manifestações em papel são as grandes culpadas pela morosidade do feito.

Historicamente as execuções fiscais tem sido apontadas como um dos protagonistas pela demora do judiciário brasileiro, o número a seguir é espantoso, a taxa de congestionamento das execuções fiscais, atinge o elevadíssimo patamar de $91,7 \%$, o que quer dizer que a cada 100 processos dessa classe que tramitaram em 2017, somente o número irrisório de 8 processos foram baixados.

São centenas de milhares de processos que em sua maioria parecem andar em círculos infinitos, são atos repetidos, intimações desnecessárias, buscas sem sucesso, processos suspensos aguardando bens dos executados, dentre outros, o processo eletrônico pode e muito provavelmente vai reduzir o tempo estimado para realização de atos processuais meramente burocráticos.

Sabe-se, por exemplo, que a exceção de pré-executividade não é nada além de

um meio de defesa incidental, em que o executado, munido de prova documental e sem a necessidade de dilação probatória provoca o julgador dentro do processo de execução para arguir questão de ordem pública ${ }^{17}$

Assim, garante ao processo de execução celeridade, afinal o juiz pode conhecer a qualquer tempo e tem o poder discricionário de extinguir a execução acolhendo a prescrição, por exemplo.

17 BARROSO, Darlan. Manual de direito processual civil: Execução. São Paulo: Manole, 2007, p. 334 . 
ALBERGARIA NETO, Jason; LOPES JÚNIOR, Newton de Araújo. O princípio constitucional da razoável duração do processo e a implementação do processo judicial eletrônico como forma de garantir celeridade aos litígios. Revista Eletrônica Direito e Política, Programa de Pós-Graduação Stricto Sensu em Ciência Jurídica da UNIVALI, Itajaí, v.16, n.1, 10 quadrimestre de 2021. Disponível em: www.univali.br/direitoepolitica - ISSN 1980-7791

Conclui-se, portanto, que sem a informatização de processos, redução da burocracia, aumento de investimentos em tecnologia o judiciário permanecera possuindo alarmantes números de desempenho.

O processo físico possibilitar inúmeras manobras inclusive para advogados que usam da falta de eficiência da justiça para postergar os processos, os denominados embargos de gaveta (prática comum quando o advogado faz carga do processo físico e permanece com ele guardado por semanas, até meses) não serão mais possíveis, inúmeros procedimentos certamente serão reduzidos e acelerados.

Existem inúmeros casos clássicos de desperdício de dinheiro público, desperdício de tempo das partes, repetição de atos que somados postergam a solução dos litígios.

A demora para garantir a satisfação do direito via processo judicial, não deve e não pode gerar dano a quem precisou invocar o judiciário para resguardar seus direitos, o que se vê em Cândido Dinamarco:

Num dos pólos desse binário de forças estão os pesos que inclinam o sistema para a efetividade do processo executivo. A efetividade do processo é uma das preocupações da moderna doutrina e corresponde à ideia instrumentalista de que o processo deve ser apto a produzir o melhor resultado possível, seja para a plena atuação do direito material, seja para a integral pacificação dos litigantes. Para obter esses bons resultados, o sistema arma-se de meios executivos e os aperfeiçoa, inclusive mediante repúdio a preconceitos tradicionais herdados, como os que empeciam a execução específica das obrigações infungíveis ou de dar coisa certa. ${ }^{18}$

Resta evidente a dificuldade do poder judiciário em sobrepor os princípios constitucionais, entretanto, fica evidente que em muitos casos a razoável duração do processo tem perdido protagonismo, o que se confirma que a preocupação exacerbada com o procedimento, torna o procedimento cada vez menos eficaz, o processo eletrônico pode ser importante ferramenta para solucionar essas questões.

18 DINAMARCO, Cândido. Execução civil. São Paulo: Malheiros, 2002, p. 321. 
ALBERGARIA NETO, Jason; LOPES JÚNIOR, Newton de Araújo. O princípio constitucional da razoável duração do processo e a implementação do processo judicial eletrônico como forma de garantir celeridade aos litígios. Revista Eletrônica Direito e Política, Programa de Pós-Graduação Stricto Sensu em Ciência Jurídica da UNIVALI, Itajaí, v.16, n.1, 10 quadrimestre de 2021. Disponível em: www.univali.br/direitoepolitica - ISSN 1980-7791

\section{OS DESAFIOS CRIADOS PELAS DifERENTES PLATAFORMAS DO PROCESSO ELETRÔNICO NO TRIBUNAL DE JUSTIÇA DE MINAS GERAIS}

Primeiramente, imperioso mencionar que é evidente que inovações tecnológicas demandam tempo para adaptação independente da área de aplicação, mas principalmente no setor jurídico, área conhecida por seu conservadorismo e formalismo é necessário aguardar o aprimoramento do processo judicial eletrônico.

Ocorre que, a digitalização dos processos judiciais vem causando inúmeros transtornos para todos os operadores do direito, inclusive porque a existência de inúmeras plataformas no mesmo tribunal de justiça vem dificultando ainda mais a utilização do sistema.

No presente estudo vamos abordar alguns problemas específicos do Tribunal de Justiça de Minas Gerais que possui sistemas diferentes para a $1^{a}$ instância denominado PJE, para $2^{\mathrm{a}}$ instância denominado JPE e para os Juizados Especiais denominado Projudi, trata-se de situação ilustrativa de como o processo eletrônico pode gerar inúmeras dificuldades ao invés de simplificar processos.

Senão vejamos, um advogado além de ter que adquirir seu certificado digital, necessita instalar inúmeros programas no seu computador para utilização de plataformas diferentes do mesmo tribunal.

Exemplificando os inúmeros obstáculos que a implementação de sistemas diferentes na mesma jurisdição sem o devido treinamento acarreta, são as centenas de chamados recebidos pelo suporte do Processo Judicial Eletrônico.

São casos de processos físicos que possuem recursos no formato eletrônico, cumprimentos de sentença de origem física que devem ser distribuídos em formato eletrônico, autos eletrônicos que demandam a expedição de documentos físicos, são dezenas de situações que as diligências são conflitantes e que fatalmente vem contribuindo para dificultar a solução dos litígios. 
ALBERGARIA NETO, Jason; LOPES JÚNIOR, Newton de Araújo. O princípio constitucional da razoável duração do processo e a implementação do processo judicial eletrônico como forma de garantir celeridade aos litígios. Revista Eletrônica Direito e Política, Programa de Pós-Graduação Stricto Sensu em Ciência Jurídica da UNIVALI, Itajaí, v.16, n.1, 10 quadrimestre de 2021. Disponível em: www.univali.br/direitoepolitica - ISSN 1980-7791

Como se não bastasse, o mesmo Tribunal de Justiça possui plataformas diferentes, um advogado ou servidor não possui meios para realizar uma diligência em um sistema único, necessários logins diferentes, acessos diferentes, determinados programas funcionam melhor com determinado navegador outros não.

É medida que se impõe que o Egrégio Tribunal de Justiça de Minas Gerais unifique seus sistemas, um caso simples e de fácil visualização é sobre o envio de arquivos, até o tamanho dos arquivos possíveis de serem remetidos ao judiciário são diferentes, e quase unânime entre os advogados que os sistemas vem gerando maior esforço, maios gasto e principalmente maior tempo na efetivação das diligências.

A unificação das plataformas da justiça estadual é essencial para garantir a razoável duração do processo, o cenário ideal seria um sistema unificado nacionalmente.

Pelo princípio da instrumentalidade, diz-se que o processo deve servir como meio idôneo de realizar o direito das partes, a implementação do processo eletrônico não pode ser um obstáculo para efetivação de direitos.

Resta claríssimo que o devido processo legal deve proteger as partes, o processo deve terminar o quanto antes, a efetividade da justiça está vinculada a celeridade da justiça, não se pode permitir que por questões administrativas, a justiça seja prejudicada.

O presente trabalho tem o intuito de demonstrar que a informatização é essencial para tentar diminuir a morosidade da justiça, mas o caso de Minas Gerais é simbólico, um advogado em Minas possui diversas plataformas, mas não é só, um advogado que atua em outros estados possui dezenas, até centenas de plataformas para atuar, são questões meramente administrativas que impedem uma boa prática jurídica.

Deve-se evitar a todo custo que as inovações tecnológicas sejam obstáculos para acelerar processos, todo o investimento e tecnologia devem ser em prol dos 
ALBERGARIA NETO, Jason; LOPES JÚNIOR, Newton de Araújo. O princípio constitucional da razoável duração do processo e a implementação do processo judicial eletrônico como forma de garantir celeridade aos litígios. Revista Eletrônica Direito e Política, Programa de Pós-Graduação Stricto Sensu em Ciência Jurídica da UNIVALI, Itajaí, v.16, n.1, 10 quadrimestre de 2021. Disponível em: www.univali.br/direitoepolitica - ISSN 1980-7791

jurisdicionados que tem como princípio constitucional a garantia constitucional da razoável duração do processo, não o contrário.

\section{CONSIDERAÇÕES FINAIS}

Apesar da recente informatização dos processos judiciais e da criação de novas leis, regulamentos, regimentos para a regulamentação do processo eletrônico no Brasil, torna-se cada vez mais importante aumentar os investimentos em equipamentos e principalmente em treinamentos para os operadores de direito, afinal não basta simplesmente digitalizar os processos para que o sistema tenha seu funcionamento pleno.

Nesse contexto, a informatização da justiça vem gerando grande expectativa na sociedade, mas em especial naqueles que convivem com o processo eletrônico diariamente, sejam eles: servidores, advogados, juízes, desembargadores, ministros, membros do judiciário em geral.

Conforme demonstrado neste artigo, a razoável duração do processo ganhou protagonismo ao receber status de garantir constitucional e a digitalização dos processos judiciais vêm como uma nova ferramenta que possibilita que o jurisdicionado tenha acesso a uma justiça justa, mas não só isso, que a prestação jurisdicional ocorra em tempo hábil, incluindo a tutela satisfativa.

No presente estudo, demonstrou-se que apesar da importante e necessária preocupação com a informatização da justiça, o treinamento de servidores e membros do judiciário é tão importante como a informatização, inclusive porque existem inúmeras críticas a forma como vem sendo implementado o processo eletrônico.

As críticas ecoam de todas os lados, sejam elas relacionadas ao custo do certificado digital, das constantes falhas nos sistemas, da ausência de padronização entre os tribunais, do grande problema de instabilidade das 
ALBERGARIA NETO, Jason; LOPES JÚNIOR, Newton de Araújo. O princípio constitucional da razoável duração do processo e a implementação do processo judicial eletrônico como forma de garantir celeridade aos litígios. Revista Eletrônica Direito e Política, Programa de Pós-Graduação Stricto Sensu em Ciência Jurídica da UNIVALI, Itajaí, v.16, n.1, 10 quadrimestre de 2021. Disponível em: www.univali.br/direitoepolitica - ISSN 1980-7791

conexões de internet no Brasil, da falta de preparo dos servidores, da velocidade que os autos retornam para os juízes, dentre outras inúmeras críticas.

Para melhor entendimento, esclarece-se que a nova legislação processual possui inúmeros avanços que tendem a garantir um processo mais célere para todas as partes, inclusive o viés garantista do novo código de processo civil é de se destacar juntamente com o protagonismo dado a Constituição Federal em relação a lei ordinária.

Ocorre que, não se pode colocar todos os problemas causados por décadas e décadas de má gestão na justiça brasileira, além da criação de leis sem propósito e da cultura exacerbada de litígios na conta do processo eletrônico, nem requerer seja solucionada pela simples informatização dos processos em tempo recorde.

Nesse contexto, a harmonização de princípios constitucionais com a legislação pátria, principalmente no que tange a normatização do processo judicial eletrônico, desde meados da década de 90, passando pelas leis 10.259/2001, 11.419/2006, até os dias hoje, tem ganhado forte protagonismo no judiciário brasileiro.

Como exposto neste artigo, toda inovação tecnológica que é passível de ser utilizada em larga escala para acelerar os ritos processuais, diminuir a burocracia processual e ainda facilitar a vida dos operadores do direito deve ser utilizada, o cerne da questão tem sido a forma de sua implementação, afinal em muitos tribunais, os sistemas têm sido criados de forma apressada e sua instalação tem ocorrido de forma extremamente intempestiva.

Não se pode simplesmente tornar o processo eletrônico o salvador de todos os problemas existentes no judiciário, a situação é gravíssima e evidentemente, salvo raríssimos casos o princípio da razoável duração do processo é figura meramente decorativa no judiciário nacional.

Os números do Conselho Nacional de Justiça são alarmantes, afinal 80,1 milhões de processos em tramitação, somados com a intensa cultura de judicialização do 
ALBERGARIA NETO, Jason; LOPES JÚNIOR, Newton de Araújo. O princípio constitucional da razoável duração do processo e a implementação do processo judicial eletrônico como forma de garantir celeridade aos litígios. Revista Eletrônica Direito e Política, Programa de Pós-Graduação Stricto Sensu em Ciência Jurídica da UNIVALI, Itajaí, v.16, n.1, 10 quadrimestre de 2021. Disponível em: www.univali.br/direitoepolitica - ISSN 1980-7791

país, tornará impossível uma solução em tempo razoável para as partes, inviabilizando o sistema judiciário brasileiro.

No ritmo atual das demandas, somente após 31 meses o estoque de processos seria zerado, o número é constrangedor e medidas devem ser tomadas pelo poder legislativo em conjunto com o poder judiciário.

O Estado tem e deve zelar pela razoável duração do processo, mas a expectativa criada em torno do PJE pode ter um efeito reverso, obviamente o processo eletrônico não pode ser a única solução, inclusive porque a implementação do processo eletrônico de forma intempestiva e sem a devida maturação pode acarretar outros problemas, como por exemplo: o acúmulo de processos conclusos para decisões, afinal com o fim da necessidade de um servidor realizar a triagem das petições físicas, os autos tem retornado rapidamente para nova decisão do magistrado.

Para solucionar o conflito existente entre a razoável duração do processo, a implementação do processo eletrônico e a falta de treinamento dos operadores de direito, necessário que haja investimento de grande porte permanente em inúmeras áreas. Os advogados devem estar mais bem preparados para minorar falhas, os servidores para conseguirem dar o devido andamento aos feitos, imperioso que os tribunais forneçam equipamentos a altura da tecnologia criada.

Além disso uma das coisas mais importantes para facilitar o funcionamento do sistema é que o Conselho Nacional de Justiça regulamente o processo eletrônico de forma que exista no mínimo um padrão entre as plataformas, afinal são dezenas talvez centenas de programas que variam inclusive dentro do próprio tribunal.

Diante de tal cenário resta clara a importância da informatização da justiça, mas evidente que existe um risco de atacar uma das causas da morosidade e deixar de lado outras inúmeras providências que devem ser tomadas para garantir um processo mais célere. 
ALBERGARIA NETO, Jason; LOPES JÚNIOR, Newton de Araújo. O princípio constitucional da razoável duração do processo e a implementação do processo judicial eletrônico como forma de garantir celeridade aos litígios. Revista Eletrônica Direito e Política, Programa de Pós-Graduação Stricto Sensu em Ciência Jurídica da UNIVALI, Itajaí, v.16, n.1, 10 quadrimestre de 2021. Disponível em: www.univali.br/direitoepolitica - ISSN 1980-7791

A hipótese mencionada na introdução dessa forma resta comprovada, pois apesar da evidente necessidade de informatização dos processos judiciais, não basta simplesmente que os processos sejam digitalizados, afinal é necessário investir em softwares mais eficazes, equipamentos e principalmente no treinamento dos servidores, afinal, são os servidores do judiciário que vão operar os sistemas.

Ademais, resta claro que os autos eletrônicos evidentemente retornaram para conclusão - momento em que o juiz profere decisões e despachos - de forma mais célere, sem a necessidade de toda triagem que era realizada com os autos físicos, daí também importante gargalo que deve ser ajustado, qual seja: a ínfima quantidade de juízes para decidir milhares de processos.

Para tanto, a legislação processual e a implementação de novas tecnologias devem caminhar em harmonia fina para que tenham o protagonismo necessário. Afinal é imperioso que ao invés de gerar uma expetativa exacerbada sem atingir seu resultado, o processo eletrônico se fortaleça e aumente cada vez mais seu alcance para que em breve a informatização do sistema judiciário alcance níveis nunca vistos.

Daí a importância da inserção de tecnologias no sistema judiciária, aumento de investimentos, treinamento de servidores e desenvolvimento de softwares para que um dia a justiça possa se tornar integralmente digital, fato que certamente acarretará maior celeridade no trâmite processual em respeito a garantia constitucional da razoável duração do processo.

\section{REFERÊNCIAS DAS FONTES CITADAS}

ALMEIDA FILHO, José Carlos de Araújo. Processo eletrônico e teoria geral do processo eletrônico: a informatização judicial no Brasil. 1a ed. Rio Janeiro: Forense, 2007. 
ALBERGARIA NETO, Jason; LOPES JÚNIOR, Newton de Araújo. O princípio constitucional da razoável duração do processo e a implementação do processo judicial eletrônico como forma de garantir celeridade aos litígios. Revista Eletrônica Direito e Política, Programa de Pós-Graduação Stricto Sensu em Ciência Jurídica da UNIVALI, Itajaí, v.16, n.1, 10 quadrimestre de 2021. Disponível em: www.univali.br/direitoepolitica - ISSN 1980-7791

ATHENIENSE, Alexandre. Comentários à Lei 11.419/06 e as práticas processuais por meio eletrônico nos Tribunais brasileiros. Curitiba: Juruá Editora, 2010.

BARBOSA, Rui. Oração aos moços. Edição popular anotada por Adriano da Gama Kury. 5 ed. Rio de Janeiro: Fundação Casa de Rui Barbosa, 1997.

BARROSO, Darlan. Manual de direito processual civil: Execução. São Paulo: Manole, 2007.

BRASIL. Lei 5.869, de 11 de janeiro de 1973. Código de Processo Civil de $1973 . \quad$ Disponível em: <www.planalto.gov.br/ccivil_03/leis/I5869compilada.htm>. Acesso em: 08 jun. 2019.

BRASIL. Constituição da República Federativa do Brasil de 1988. Disponível em: <http://www.planalto.gov.br/ccivil_03/constituicao/constituicaocompilado.htm> Acesso em: 08 jun. 2019.

BRASIL. Lei 9.800, de 26 de maio de 1999. Permite às partes a utilização de sistema de transmissão de dados para a prática de atos processuais. Disponível em: <http://www.planalto.gov.br/ccivil_03/leis/19800.htm>. Acesso em: 08 jun. 2019.

BRASIL. Constituição (1988). Emenda constitucional no 45, de 30 de dezembro de 2004. Altera dispositivos dos arts. 50, 36, 52, 92, 93, 95, 98, 99, $102,103,104,105,107,109,111,112,114,115,125,126,127,128,129$, 134 e 168 da Constituição Federal, e acrescenta os arts. 103-A, 103B, 111-A e 130-A, e dá outras providências. Disponível em: <http://www.planalto.gov.br/ccivil_03/constituicao/emendas/emc/emc45.htm>. Acesso em: 27 jan. 2020.

BRASIL. Lei no 10.259, de 12 de julho de 2001. Dispõe sobre a instituição dos Juizados Especiais Cíveis e Criminais no âmbito da Justiça Federal. Disponível em: <http://www.planalto.gov.br/ccivil_03/leis/leis_2001/l10259.htm>. Acesso em: 27 jan. 2020.

BRASIL. Projeto de lei no 5828, de 04 de dezembro de 2001. Dispõe sobre a informatização do processo judicial e dá outras providências. Disponível em: <https://www.camara.leg.br/proposicoesWeb/fichadetramitacao?idProposicao=4 1619>. Acesso em: 27 jan. 2020.

BRASIL. Lei 11.419, de 19 de janeiro de 2006. Dispõe sobre a informatização do processo judicial; altera a Lei no 5.869, de 11 de janeiro de 1973 - Código de Processo Civil; e dá outras providências. Disponível em: <http://www.planalto.gov.br/ccivil_03/_Ato2004-2006/2006/Lei/L11419.htm>. Acesso em: 08 jun. 2019. 
ALBERGARIA NETO, Jason; LOPES JÚNIOR, Newton de Araújo. O princípio constitucional da razoável duração do processo e a implementação do processo judicial eletrônico como forma de garantir celeridade aos litígios. Revista Eletrônica Direito e Política, Programa de Pós-Graduação Stricto Sensu em Ciência Jurídica da UNIVALI, Itajaí, v.16, n.1, 10 quadrimestre de 2021. Disponível em: www.univali.br/direitoepolitica - ISSN 1980-7791

BRASIL. Lei 11.280, de 16 de fevereiro de 2006. Altera os arts. 112, 114, 154, 219, 253, 305, 322, 338, 489 e 555 da Lei no 5.869, de 11 de janeiro de 1973 Código de Processo Civil, relativos à incompetência relativa, meios eletrônicos, prescrição, distribuição por dependência, exceção de incompetência, revelia, carta precatória e rogatória, ação rescisória e vista dos autos; e revoga o art. 194 da Lei no 10.406, de 10 de janeiro de 2002 - Código Civil. Disponível em: <http://www.planalto.gov.br/ccivil_03/_Ato2004-2006/2006/Lei/L11280.htm>.

Acesso em: 08 jun. 2019.

BRASIL. Lei no 11.419, de 19 de dezembro de 2006. Dispõe sobre a informatização do processo judicial; altera a Lei no 5.869 , de 11 de janeiro de 1973 - Código de Processo Civil; e dá outras providências. Disponível em: <http://www.planalto.gov.br/ccivil_03/_ato2004-2006/2006/lei/l11419.htm>.

Acesso em: 27 jan. 2020.

BRASIL. Lei 13.105, de 16 de março de 2015. Código de Processo Civil de 2015. Disponível em: <http://www.planalto.gov.br/ccivil_03/_Ato20152018/2015/Lei/L13105.htm>. Acesso em: 08 jun. 2019.

BRASIL. Justiça em Números 2018: ano-base 2017/Conselho Nacional de Justiça. Brasília: CNJ, 2018. Disponível em: <https://www.cnj.jus.br/wpcontent/uploads/2011/02/8d9faee7812d35a58cee3d92d2df2f25.pdf >. Acesso em: 27 jan. 2020.

DINAMARCO, Cândido. Execução civil. São Paulo: Malheiros, 2002.

DONIZETTI, Elpídio. Curso de direito processual civil. 19a ed. São Paulo: Atlas, 2016.

ESPANHA. Lexnet. Presentación de Escritos Iniciados de Ejecución. Disponível em: <https://lexnetjusticia.gob.es/documents/20181/803631/20181010_GD_SF_MD _LexNET_Guia_Iniciador_Ejecucion/54e68117-3371-4d85-9d8b-

e2535d1bd2c2>. Acesso em: 20 jun. 2019.

LENZA, Pedro. Direito Constitucional esquematizado. $16^{a}$ ed. São Paulo: Saraiva, 2012.

LUCON, Paulo Henrique dos Santos. Duração Razoável e Informatização do processo judicial. Panóptica, Vitória, ano 1, n. 8, p. 368-384. Maio-Junho, 2007. Disponível em: <http://www.panoptica.org/seer/index.php/op/article/view/Op_2.4_2007_368384/236>. Acesso em: 20 jun. 2019. 
ALBERGARIA NETO, Jason; LOPES JÚNIOR, Newton de Araújo. O princípio constitucional da razoável duração do processo e a implementação do processo judicial eletrônico como forma de garantir celeridade aos litígios. Revista Eletrônica Direito e Política, Programa de Pós-Graduação Stricto Sensu em Ciência Jurídica da UNIVALI, Itajaí, v.16, n.1, $1^{\circ}$ quadrimestre de 2021. Disponível em: www.univali.br/direitoepolitica - ISSN 1980-7791

OAB. Os cinco maiores problemas do Processo Eletrônico. Disponível em: $<$ https://www.oab.org.br/noticia/25217/oab-aponta-os-cinco-maioresproblemas-do-processo-judicial-eletronico>. Acesso em: 20 jun. 2019.

PORTUGAL. Procuradoria Geral Distrital de Lisboa. Portaria 280, de 26 de agosto de 2013. Regula vários aspectos da tramitação eletrônica dos processos judiciais. em: $<$ http://www.pgdlisboa.pt/leis/lei_mostra_articulado.php?nid=1967\&tabela=leis \&so_miolo=>. Acesso em: 26 jun. 2019.

THEODORO JÚNIOR, Humberto. Curso de Direito Processual Civil. v. II. 36 ed. Rio de Janeiro: Forense, 2004.

THEODORO JÚNIOR, Humberto. Curso de Direito Processual Civil - Teoria Geral do Direito Processual Civil, processo de conhecimento e procedimento comum. v. I. 56 ed. Rio de Janeiro: Forense, 2015.

TUCCI, José Rogério Cruz e. Tempo e processo. São Paulo: Revista dos Tribunais, 1997.

WAMBIER, Luiz Rodrigues; WAMBIER, Teresa Arruda Alvim (Coord.). Temas essenciais do novo CPC: análise das principais alterações do sistema processual civil brasileiro. São Paulo: Editora Revista dos Tribunais, 2016.

RECEBIDO EM: MAR/2020

APROVADO EM: JUL/2020 